\title{
Continuous Production of Organic Acids from Palm Oil Mill Effluent with Sludge Recycle by the Freezing-Thawing Method
}

\begin{abstract}
The performance of the anaerobic treatment of palm oil mill effluent for organic acids production at a short retention time of less than 5 days was assessed by incorporating a sludge recycle system with no $\mathrm{pH}$ control except by adding calcium carbonate. The system could be operated successfully for a 3.5-day retention time at $\mathrm{pH} 5$. The sludge solids in the treated effluent were separated by a freezing-thawing technique and it was partly recycled back to the reactor. The thawed clarified POME solution contained a low SS of 2,200-3,500 mg/L. The organic acids production with a concentration of $10-14 \mathrm{~g} / \mathrm{L}$ was essentially similar to the treatment for a 5-day retention time without a sludge recycle. Hence by incorporating a sludge recycle system with the freezing-thawing method, the retention time for the treatment could be reduced without affecting the organic acids generation.
\end{abstract}

Keyword: Organic Acids, Palm Oil Mill Effluent, Anaerobic Treatment, Recycle, FreezingThawing 